\title{
Win some, lose some: Hypermnesia for actions reflects increased item-specific processing
}

\author{
ULRICH OLOFSSON \\ Umeå University, Umeå, Sweden
}

\begin{abstract}
Memory for simple action phrases (e.g., "Break a match") improves when subjects perform the actions at study. The relative contribution of item-specific and relational processing to this enactment effect has been an issue of considerable debate. It was addressed in the present study by examining hypermnesia in a multiple-test free recall paradigm, based on the assumptions that itemspecific processing increases the probability of intertest gains and relational processing protects against intertest forgetting (e.g., Burns, 1993; Klein, Loftus, Kihlstrom, \& Aseron, 1989). It was found that the enactment condition produced both significantly more gains and more losses than did the nonenactment condition, resulting in a net gain (hypermnesia) for the enactment condition. The results suggest that enactment promotes item-specific processing at the expense of relational processing.
\end{abstract}

It is a well-established empirical fact that memory for action phrases (e.g., "Break a match") benefits greatly when the subjects perform the actions relative to when they simply read or listen to the phrases (for a review, see Cohen, 1989; Engelkamp \& Zimmer, 1994). The source of this "enactment" effect remains disputed, however. Although it is generally agreed that enactment adds itemspecific information to the "memory trace" (e.g., Bäckman, Nilsson, \& Chalom, 1986; Helstrup, 1986; Nyberg, 1993; Saltz \& Donnenwerth-Nolan, 1981; Zimmer \& Engelkamp, 1989), the effect on relational processing is unclear.

Item-specific processing is assumed to increase the distinctiveness of an item in memory by emphasizing features that discriminate a particular item from other items, whereas relational processing is assumed to increase the organization of items in memory by focusing on features that are shared and by encoding interitem associations (Hunt \& Einstein, 1981). Some authors claim that the enactment effect is due to increased relational processing, as well as item-specific processing (e.g., Bäckman et al., 1986); others argue that the effect is due exclusively to increased item-specific processing (e.g., Engelkamp \& Zimmer, 1994, 1996; Zimmer \& Engelkamp, 1989). Engelkamp (1995) has even suggested that enactment may hinder relational processing by forcing attention to itemspecific information and by hampering encoding of relational information.

This research was supported by a grant from the Swedish Council for Research in the Humanities and Social Sciences. Final preparation of the paper was supported by a postdoctoral fellowship awarded by the Swedish Foundation for International Cooperation in Research and Higher Education. The author is grateful to Reed Hunt, Geoffrey Loftus, and Jonathan Schooler for valuable comments on a previous draft of this article. Correspondence should be addressed to U. Olofsson, now with the Department of Psychology, University of British Columbia, Vancouver, BC, Canada V6T 1 Z4 (e-mail: uolofsson(a)cortex.psych.ubc.ca).
Both views draw on comparisons of adjusted ratio of clustering (ARC) scores (Roenker, Thompson, \& Brown, 1971) - an index of organization in free recall of categorized lists - for support. Some researchers have reported significantly higher ARC scores in recall for subject-performed tasks (SPTs) than in recall for verbal tasks (VTs) (Bäckman et al., 1986), indicating increased relational processing, whereas others have failed to find any difference (Engelkamp \& Zimmer, 1996; Zimmer \& Engelkamp, 1989), suggesting that enhanced relational processing does not contribute to the enactment effect. Engelkamp and Zimmer (1996) recently tested the hypothesis that differences in materials were responsible for the previous incompatible results. For example, the study by Bäckman et al. (1986) involved real objects, whereas Zimmer and Engelkamp's (1989) experiments involved imaginary objects. Also, the lists in the former study were organized according to object categories, and the lists in the latter study were organized according to action categories. However, after controlling for these differences, Engelkamp and Zimmer (1996) still did not find any reliable difference between the ARC scores in SPT and VT conditions, and they maintained that the enactment effect is due exclusively to item-specific processing.

There are serious problems with these comparisons of clustering, though. The conclusion that enactment does not increase relational processing is based on a null effect - the failure to find a difference in ARC scoresand if such a conclusion is to have any credibility at all, then the measures must at least be sensitive and reliable enough to permit the detection of a difference. However, the ARC scores reported by Engelkamp and Zimmer (1996) seem far too unsystematic and variable in this regard; mean differences (VT - SPT) in different conditions varied from -.12 to .35 , and standard deviations varied from .28 to 1.11 (ARC scores of 0 and 1 represent chance and perfect clustering, respectively). Furthermore, 
the generality of results from ARC comparisons is restricted because categorized materials have to be used.

The present study was intended to resolve this issue by comparing SPTs and VTs in multiple recall tests. When memory is probed with multiple tests, some items may be forgotten between tests (item losses), whereas previously unrecalled items may be recovered on later tests (item gains). Although memory performance typically declines with time, in multiple-test experiments it is often observed that the number of intertest gains is greater than the number of intertest losses, resulting in an overall increase in memory performance: A phenomenon that has been labeled hypermnesia (Erdelyi \& Becker, 1974; for a review, see Payne, 1987). The interesting thing about hypermnesia for the present purposes is that it has been shown that conditions that encourage item-specific processing increase the probability of item recoveries, whereas conditions that encourage relational processing protect against intertest forgetting (Burns, 1993; Klein, Loftus, Kihlstrom, \& Aseron, 1989). Thus, in the present study it was hypothesized that, if enactment promotes item-specific processing and not relational processing, there should be more item recoveries and more intertest forgetting after SPT encoding than after VT encoding.

This approach to examining item-specific and relational processing has several advantages over clustering measures (cf. Burns, 1993). Most importantly, it provides both a more direct measure of relational processing and an independent measure of item-specific processing. It is also a more general approach, since the materials do not have to be structured.

\section{METHOD}

\section{Subjects}

Thirty-two paid volunteers ( 13 females, 19 males; mean age = 23 years) participated in the experiment. They were all students at Umea University. Half of the subjects were assigned to the SPT condition and half to the VT condition, with approximately equal amounts of men and women in each group. The subjects were tested individually.

\section{Materials \\ Molander and Arar's (1996) norms were used to select 40 action phrases of medium familiarity. All verbs and nouns occurred only once in the list. All actions involved familiar objects (e.g., "Break a match," "Play a piano"). Sixteen permutations of the study list were prepared, one for each subject in both the SPT group and the VT group.}

\section{Procedure}

The subjects were told that they would be presented with a series of action phrases, which they were to repeat aloud and try to memorize for a subsequent memory test. The subjects in the SPT group were also asked to perform the actions symbolically. Two examples of action phrases were presented, in order to familiarize the subjects with the material and to make sure that they correctly understood the task

The action phrases were presented on a 21 -in. computer screen at a comfortable viewing distance (about $1.5 \mathrm{~m}$ ). Each action phrase was preceded by a warning tone and was displayed for $5 \mathrm{sec}$. The interstimulus interval was $500 \mathrm{msec}$.
The subjects received the first free recall test immediately after the final phrase had been displayed. They were given a response sheet with 40 lines, divided into two columns, and were asked to write down, in any order, all phrases that they could remember. They were asked to write down the noun, should they fail to recall a complete phrase.

The subjects were notified when half of the permitted time had elapsed. When time was up, the experimenter collected the response sheet, handed the subject a new sheet, and repeated the recall instruction. The procedure was then repeated a third time, which the subjects were told was the final recall test.

\section{RESULTS}

The scoring was based on nouns, because verbs and nouns were often mixed up due to the long study list and because the instruction encouraged the subjects to produce nouns if they were unable to recall whole phrases.

Table 1 displays the mean numbers of correctly recalled nouns as a function of study task and recall test and the recall components for the respective study tasks. Gains (item recoveries) were scored as nouns that were recalled on the second but not the first test in each test pair (Tests $1-2$, and Tests $2-3$, respectively). Losses (intertest forgetting) were scored as nouns that were recalled on the first but not the second test in each test pair.

Turning first to the recall data, there were reliable main effects of study task $\left[F(1,30)=16.21, M S_{\mathrm{e}}=42.11\right]$ and recall test $\left[F(2,60)=6.37, M S_{\mathrm{e}}=1.28\right]$, and a reliable interaction between the two variables $[F(2,60)=$ $\left.5.49, M S_{\mathrm{e}}=1.28\right]$. (Note that $\alpha$ was set to .05 for all analyses.) It can be seen from the table that the SPT group performed better overall than did the VT group; more importantly, the performance of the SPT group improved over tests, whereas the VT group did not show any improvement. The difference between the last and first test was $1.82( \pm 0.82)^{1}$ for the SPT group versus -0.06 $( \pm 0.82)$ for the VT group.

Turning next to the recall components, the most critical comparison concerned the overall probability of gains and losses for SPT and VT conditions. All 16 subjects in the SPT group but only 9 subjects in the VT group produced items on subsequent tests that were not initially remembered. Similarly, all 16 subjects in the SPT group but only 10 subjects in the VT group showed any intertest forgetting (the Fisher exact probability for both these outcomes is less than .01). The main effect of study

Table 1

Mean Number of Recalled Nouns and Intertest Gains and Losses for Verbal and Subject-Performed Encoding Tasks

\begin{tabular}{|c|c|c|c|c|c|}
\hline & \multicolumn{3}{|c|}{ Test } & \multicolumn{2}{|c|}{ Recall Component } \\
\hline & 1 & 2 & 3 & Gains & Losses \\
\hline \multicolumn{6}{|c|}{ Verbal Task } \\
\hline$M$ & 9.94 & 9.44 & 9.88 & 0.94 & 1.00 \\
\hline$S D$ & 4.19 & 4.13 & 4.26 & 0.86 & 0.97 \\
\hline \multicolumn{6}{|c|}{ Subject-Performed Task } \\
\hline$M$ & 14.31 & 14.91 & 16.13 & 5.13 & 3.31 \\
\hline$S D$ & 3.72 & 3.31 & 3.28 & 2.39 & 1.96 \\
\hline
\end{tabular}


task was significant $\left[F(1,30)=33.04, M S_{\mathrm{e}}=2.56\right]$, and it can be seen in the table that the SPT group produced both more gains and more losses than did the VT group. The difference between SPT and VT groups was 4.19 $( \pm 1.19)$ for gains and $2.31( \pm 1.19)$ for losses.

There was also a reliable interaction between study task and recall component $\left[F(1,30)=9.88, M S_{\mathrm{e}}=\right.$ $0.71]$. The hypermnesia for the SPT group resulted from reliably more gains than losses (the difference was 1.82 $[ \pm 0.44])$, whereas gains and losses canceled out for the VT group $(-0.06[ \pm 0.44])$.

Finally, there were some effects of less importance for the purpose of the present experiment: a main effect of recall component $\left[F(1,30)=8.61, M S_{\mathrm{e}}=0.71\right]$, due to more gains than losses overall ( 3.04 vs. 2.16); a main effect of test pair $\left[F(1,30)=8.48, M S_{\mathrm{e}}=1.07\right]$, due to more losses between the first and second test than between the second and third test (6.24 vs. 4.13$)$; and an interaction between study task and test pair $\left[F(1,30)=4.22, M S_{\mathrm{e}}=\right.$ 1.07], due to a larger difference between test pairs for the SPT group than for the VT group (1.81 vs. 0.3 ).

\section{DISCUSSION}

The purpose of the study was to examine whether the enactment effect is due to item-specific processing rather than relational processing by comparing SPTs and VTs with regard to item gains and losses. The greater number of losses in the SPT condition indicates that relational processing was poorer than in the VT condition, and the even greater number of gains suggests increased item-specific processing, resulting in a net gain (hypermnesia) for SPTs. This interpretation of the results corresponds to the reasoning of Burns (1993), who argued that the present outcome from a hypermnesia experiment - more gains and losses in a condition together with a higher overall recall level-can safely be inferred as resulting from itemspecific processing (see Burns, 1993, for details).

Hence, these results support the view that the enactment effect is due to item-specific, and not relational, processing (e.g., Engelkamp \& Zimmer, 1994, 1996; Zimmer \& Engelkamp, 1989). In fact, the results go beyond the results of Zimmer and Engelkamp (1989) in that they show that enactment may actually hinder interitem relational processing (cf. Engelkamp, 1995). Moreover, a comparison with recent results on memory for serial order underscores this conclusion. Olofsson (1996) showed that when subjects expected a test of memory for order, performance in an order-reconstruction task was significantly worse for SPTs than for VTs (a reversed enactment effect). Taken together, these results strongly suggest that item-specific processing is the dominant mode of encoding SPTs.

The reason enactment induces item-specific processing may be that when subjects enact the action phrases, they focus on each phrase as a separate unit and encode it as an isolated representation in memory. Due to the rich item information, these representations are highly accessible as separate units and may thus be recovered on a later test if not originally recalled. A consequence of a high degree of intraitem integration and a lower degree of interitem organization would be that SPTs are retrieved independently of one another: Items that are retrieved on the first test may be forgotten on a subsequent test, and vice versa. For VTs, the lower probability of forgetting and recovery suggests that these items are more relationally encoded. If a VT is recalled on the first test, the probability that it will be recalled on the second test is high, because VTs are better organized as parts of the study episode (cf. Hunt \& McDaniel, 1993).

As an alternative explanation for the difference in intertest forgetting, one might argue that the probability of forgetting an item is greater if many items are retrieved on the first recall test. That is, the difference in losses between SPTs and VTs could be an artifact of the difference in initial recall. This is an unlikely explanation of the results, however, considering that the average difference in initial recall was 4.37 items (the VT and SPT groups recalled 9.94 and 14.31 , respectively, on Test 1 ). It does not seem plausible that this moderate increase in memory load should explain significantly more losses for the SPT group. It should also be noted that, with regard to gains, there is in fact less potential for recoveries of SPTs than VTs since the number of initially unrecalled SPTs available for recovery is smaller than the number of available VTs. If anything, this would strengthen the finding that enactment produces more gains than does verbal encoding. However, it seems safest to assume that the difference in initial recall should have little effect on either gains or losses. In support of this reasoning, Payne (1986, Experiment 1A) still found more hypermnesia for pictures than for words after equating the initial recall levels. It should also be noted that the difference in net gains was larger between Test 2 and Test 3 than between Test 1 and Test 2, which is the opposite of what would be expected if hypermnesia depended on cumulative recall levels (Payne, 1986).

Finally, it should be noted that the present results qualify previous reports of a steeper initial forgetting slope for VTs than for SPTs (Nilsson, Cohen, \& Nyberg, 1989; Nyberg, Nilsson, \& Bäckman, 1992). The present data show that individual SPTs may in fact be forgotten more rapidly than VTs, but hypermnesia for SPTs should result in less forgetting overall.

\section{REFERENCES}

Bä́KMAN, L., Nilsson, L.-G., \& Chalom, D. (1986). New evidence on the nature of the encoding of action events. Memory \& Cognition. 14, 339-346

BURNS, D. J. (1993). Item gains and losses during hypermnesic recall: Implications for the item-specific-relational information distinction Journal of Experimental Psychology: Learning. Memory \& Cognition, 19, 163-173.

CoHEN, R. L. (1989). Memory for action events: The power of enactment. Educational Psychology Review. 1, 57-81.

EngelKamP, J. (1995). Visual imagery and enactment of actions in memory. British Joumal of Psychology, 86, 227-240.

EngelkamP. J., \& Zimmer, H. D. (1994). The human memory. Seattle, WA: Hogrefe \& Huber.

ENGELKAMP, J., \& ZimMER. H. D. (1996). Organisation and recall in 
verbal tasks and in subject-performed tasks. European Journal of Cognitive Psychology, 8, 257-273.

ERdelyi, M. H., \& Becker, J. (1974). Hypermnesia for pictures: Incremental recall for pictures but not for words in multiple recall trials. Cognitive Psychology, 6, 159-171.

HELSTRUP, T. (1986). Separate memory laws for recall of performed acts? Scandinavian Journal of Psychology, 27, 1-29.

Hunt, R. R., \& Einstein, G. O. (1981). Relational and item-specific information in memory. Journal of Verbal Learning \& Verbal Behavior, 21, 539-548.

Hunt, R. R., \& MCDANiEl, M. A. (1993). The enigma of organization and distinctiveness. Journal of Memory \& Language, 32, 421-445.

Klein, S. B., Loftus, J., Kinlstrom, J. F., \& AsERon, R. (1989). Effects of item specific and relational information on hypermnesic recall. Journal of Experimental Psychology: Learning, Memory, \& Cog nition, 15, 1192-1197.

LofTus, G. R., \& MAsson, M. E. J. (1994). Using confidence intervals in within-subject designs. Psychonomic Bulletin \& Review, 1, 476-490.

Molander, B., \& ARAR, L. (1996). Familiarity, emotionality, motor activity, and recallability: Swedish norms for 444 SPT items. Manuscript submitted for publication.

Nilsson, L.-G., CoHEN, R. L., \& Nyberg, L. (1989). Recall of enacted and nonenacted instructions compared: Forgetting functions. Psychological Research, 51, 188-193.

Nyberg, L. (1993). The enactment effect: Studies of a memory phenomenon. Unpublished doctoral dissertation, Umeå University, Umeå, Sweden.
NyberG, L., Nilsson, L.-G., \& BäcKMAN, L. (1992). Recall of actions, sentences, and nouns: Influences of adult age and passage of time. Acta Psychologica, 79, 245-254.

Olofsson, U. (1996). The effect of enactment on memory for order Psychological Research, 59, 75-79.

PAYNE, D. G. (1986). Hypermnesia for pictures and words: Testing the recall level hypothesis. Journal of Experimental Psychology: Learning, Memory, \& Cognition, 12, 16-29.

PAYNe, D. G. (1987). Hypermnesia and reminiscence in recall: An historical and empirical review. Psychological Bulletin, 101, 5-27.

Roenker, D. L., Thompson, C. P., \& Brown, S. C. (1971). Comparisons of measures for the estimation of clustering in free recall. Psychological Bulletin, 76, 45-48.

Saltz, E., \& Donnenwerth-Nolan, S. (1981). Does motoric imagery facilitate memory for sentences? A selective interference test. Journal of Verbal Learning \& Verbal Behavior, 20, 322-332.

ZIMMER, H. D., \& ENGELKAMP, J. (1989). Does motor encoding enhance relational information? Psychological Research, 51, 158-167.

\section{NOTE}

1. Confidence intervals for differences in within-subjects variables were computed as suggested by Loftus and Masson (1994).

(Manuscript received March 29, 1996; revison accepted for publication November 20, 1996.) 